\title{
A(S) ATIVISTA(S) DA VOZ: ANA CRISTINA CESAR E A "TELE-GRAFIA" DE AVITAL RONELL
}

THE VOICE ACTIVIST(S): ANA CRISTINA CESAR AND AVITAL RONELL'S "TELE-GRAPHY"

André Luís de Araújo*

RESUMO: A enunciação poética da brasileira Ana Cristina Cesa se levanta desejosa de novos encontros. Impulsionada pela alteridade, ávida pela conectividade, a poeta carioca aparece na cena cultural contemporânea pronta para o debate, sendo possível distender sua interlocução com a estética e a tele-grafia da filósofa norte-americana Avital Ronell. Interessa-nos, portanto, mapear os pontos de diálogo entre as autoras que evidenciam, ainda, uma aproximação com o autor argentino Jorge Luis Borges, pela identificação de posturas reconhecidas no vitalismo crescente da criacão estetica e crítica da cultura na qual estac inseridas. Em ambas, o traço do oritmo da cidade e das rus, na cono uma mera reproduça o ritmo da cidade e das ruas, năo como uma mera reprodução dialógica, mas como a produção de algo melódico e harmônico embora frenético. De algum modo, Ana Cristina antecipa o projeto de Ronell, primando pelo trabalho da escrita, pelos efeitos da leitura e da criação de sensações, retomando a singularidade que conecta e dá voz a muitos.

PALAVRAS-CHAVE: Ana Cristina Cesar; Avital Ronell; Jorge Luis Borges; voz; tele-grafia.

\author{
aluisaraujosj@gmail.com \\ Doutor em Letras Estudos Literários pela UFMG. Professor do \\ Curso de Letras e do Programa de Pós-graduação em Estudos da
Linguagem da Universidade Católica de Pernambuco (Recife - PE).
}

ABSTRACT: The poetic enunciation of the Brazilian Ana Cristina Cesar arouses desire for new encounters. Driven by otherness, eager for connectivity, the poet from Rio appears in the contemporary cultural scene ready for debate, making it possible to stretch her interlocution with the aesthetics and tele-graphy of the American philosopher Avital Ronell. We are interested, therefore, in mapping the points of dialogue between the authors that also show an approximation with the Argentinian author Jorge Luis Borges, through the identification of postures recognized in the growing vitalism of the aesthetic and critical creation of the culture in which they are inserted. culture in which they are inserted. In both, the trace of the unan and of the conversation captures the rhythm of the city and the streets, not as a mere dialogical reproduction, but as the production of something melodic and harmonic, although frantic. In some way, Ana Cristina anticipates Ronell's project, focusing on the work of writing, on the effects of reading and the creation of sensations, resuming the singularity that connects and gives voice to many.

KEYWORDS: Ana Cristina Cesar; Avital Ronell; Jorge Luis Borges; voice; tele-graphy. 
1. Nos anos da ditadura militar no Brasil (1964-1985), surge uma geração de poetas que tinha como marco a produção de suas obras de forma independente, a baixo custo e comercializadas em circuitos alternativos, geralmente de máo em mão, particularmente em bares e universidades. Nasce, assim, um circuito denominado poetas marginais, pelo fato de estarem à margem das publicações das grandes editoras.

\section{INTRODUÇÃO}

A poeta brasileira Ana Cristina Cesar (1952-1983) dizia que calçava luvas para escrever. Em que pese essa observação, nada nos impede de perceber a forte impressão de intensidade que predomina em tudo que se encontra em seu acervo, no Instituto Moreira Salles, no Rio de Janeiro: correspondências, originais de poesia, artigos de periódicos, material de divulgação, documentos pessoais, fotografias, dedica tórias, livros, cartas, posta is e dois documentários. A autora surge neles como uma presença que, aos poucos, transforma-se em urgência aflitiva.

Nota-se que ela viveu intensa mente e que se destacou por mérito próprio. Sua coleção é rica em informações, que possibilitam não apenas (re)conhecer a escritora Ana C. - modo como costumava assinar seus textos -, como também uma época da história e da literatura brasileiras. A geração mimeógrafo ${ }^{1}$, a poesia marginal, o teatro ma mbembe, a ditadura militar e outras manifestações ocorridas a partir da década de 1960 podem ser resgatados por meio da consulta aos documentos.

Dessa referencialidade formadora, Ana Cristina desponta com uma nova maneira de conceber a literatura, fascinada por exaurir a totalidade discursiva de uma fabulação sem constrangimentos. Em sua poética, o ser se impõe e indaga pela construção de um processo de subjetivação que passa pelo corpo - potência agenciadora da escrita literária, à maneira deleuzeana - imerso na cultura, locus de enfrentamento com o poder e suas complexas inter-relações.

Precisamente nesse espaço, a autora aclama a vida que se quer livre, que não poupa esforços para mostrar a capacidade da resistência humana em ir muito além de relações dicotômicas ou de classificações taxonômicas: ser constituído e em constituição, pensado e em pensamento, sexuado ou assexuado. Tem lugar nesse cenário o debate sobre o corpo e o lugar do desejo, os valores da mulher e a redefinição do feminino e o questiona mento intempestivo: o que pode um corpo?

Nesse sentido, compreender a poética de Ana Cristina é proclamar com ela a universalidade da linguagem, uma experiência que se faz física, geograficamente, lidando com imagens do mundo e do pensamento, de forma que signifiquem posturas, a tos visíveis, dea mbulação, movimento. Uma infinidade de signos, um devir louco de pluralidades se sobrepõem, cria m e estabelecem relações que, antes de facilitar localizações dentro de uma série, aguçam novas chaves de leitura que tentam especular seu funcionamento. "Não sou idêntica a mim mesmo/ 
sou e não sou ao mesmo tempo, no mesmo lugar e sob o mesmo ponto de vista/ Não sou divina, não tenho ca usa/ Não tenho razão de ser nem finalidade própria:/ Sou a própria lógica circundante” (CESAR, 1985, p. 59).

A estética marginal em Ana Cristina Cesar e a produção artesanal de seus primeiros livros foram o passo inicial e decisivo para a criação de seu primeiro círculo de leitores, o que lhe garantiu acesso ao sistema editorial fechado. Aproximando-se de seu público, os autores dessa geração recusavam o esquema de promoções e a despersonalização do livro como mercadoria. Referindose a Chico Alvim como "poeta maduro e com suficiente respaldo para ser publicado em editora" (CESAR, 1999, p. 201), Ana Cristina mostrava, assim, que ta mbém compreendeu o significado político daquela opção inicial, como se pode atestar pela repercussão de sua obra publicada postumamente, madura para franquear o espaço que lhe cabia.

Por outro lado, seu percurso não se valida apenas no que a distingue dos demais poetas margina is de sua geração - portadora de um estilo próprio, um trabalho arrojado com a linguagem -, tampouco no evento de sua morte, mas no compromisso com a cultura e com a teoria literária, desvinculada do desejo de consagração.
Desde cedo, Ana Cristina entra no terreno da ironia e de suas contradições, desconfiando da sinceridade da pena do escritor e do cristalino das superfícies da linguagem. Entra para simular, para poder dizer, negar a crença na palavra como espelho da realidade, e se pergunta: "quem é esse eu lírico que se derrama em versos? Será sincero? Reflete o Autor? Mascara?” (CESAR, 1999, p. 202).

Mesmo sua correspondência, lida nessa tensão, funciona como verdade nos interstícios da realidade. Seus textos exigem, por isso, a cumplicidade especial do leitor, fazem pensar, tentam diminuir distâncias, revolucionam o próprio ato de escrever e de produzir a arte. Reproduzem um labirinto que se ramifica, levando-nos aos mais variados lugares, conexões, paisagens de fuga, não o território íntimo de quem os escreveu. Sua poética é produção e não representação de verdades.

Essa questão é tema, ainda, de vários de seus textos críticos reunidos em Crítica e Tradução (1999) e se pode observar em sua biblioteca particular, mantida em seu acervo pessoal no IMS, que ela era leitora de autores que partilham de certo universo de pensamento comum, que se afastam de uma concepção meramente representacional da arte. Há obras lidas e anotadas de nomes como Octavio Paz, Jorge Luis Borges, Michel Foucault,

EM TESE BELO HORIZONTE $\quad$ v. $26 \quad$ N. 2 MAI0-Ago. 2020 ARAÚJO. A(s) ativista(s) da voz: Ana Cristina Cesar e a "tele-grafia" [...] $\quad$ P. 202-221

Teoria, Crítica Literária, outras Artes e Mídias 
Roland Barthes, Antonin Artaud, Jacques Derrida, Maurice Blanchot, Gilles Deleuze, Félix Guattari, bem como poetas e teóricos muito difundidos por sua geração e que fizeram parte da ementa do curso Poesia Moderna Traduzida, que Ana Cristina daria, na PUC do Rio de Janeiro, no primeiro semestre de 1983: T. S. Eliot, Ezra Pound, Charles Baudelaire, Mallarmé, Walt Whitman, Maiakóvski, entre outros.

De posse desses pressupostos, vamos fazer com ela o trabalho da linguagem, trazendo para a discussão a potência da escrita fragmentária. Nessa perspectiva, ao criar, vemos como Ana Cristina coloca em prática sua habilidade crítica, avaliando seus procedimentos, estabelecendo parâmetros, fazendo compa rações, marcando sua erudição, acenando que estava antenada com a cena histórica, literária e contemporânea. Isso, para a autora era um exercício consciente, ético e estético, impossível de se desvencilhar da poesia que escrevia; verdadeira construção de real, texto autônomo, independente do mundo, objeto a ser manuseado e recriado pelo leitor.

Nessa perspectiva, abandonamos o senso comum de uma leitura atrelada a intenções pessoais da autora, em nome de um entendimento do plano de composição de seu texto, sem a pretensão de decifrá-lo, sem jogos de adivinhação a cada página. Não estamos num jogo de espionagem. Afinal, como ela mesma dizia: "Ao produzir literatura, eu faço rasgos de verdade, eu tenho uma opção pela construção, ou melhor, não consigo transmitir para você uma verdade acerca da minha subjetividade. É uma impossibilidade até". (CESAR, 1999, p. 273). Além disso, com o passar do tempo, sobretudo após sua morte e a consolidação de sua obra, não se está estabelecendo um elemento Ana C., mas muitos, recuperados de muitas e variadas formas. Temos, pois, adiante um desafio: encontrar-nos com esta performer, não apenas na letra de seus textos, fazendo a exumação de seus escritos, mas reconhecermos o que distingue sua voz. Não simplesmente o sujeito Ana Cristina Cesar, mas um dispositivo literário, que lida com a zona instável dos segredos da intimidade, conta minado pelas evidências da vida pública e a letra autossuficiente da literatura, onde vem ganhando forca a cada dia a persona Ana C., capaz de nos colocar à distância, de nos ironizar, ou de refutar boa parte dos estereótipos com os quais a confundimos.

Aliás, Ana admitia que queria mobilizar um interlocutor com um tipo de escrita mais imediato como o das cartas, diários, postais, o que reconhecia como um traço de uma literatura feminina, de âmbito muito particular ${ }^{2}$. A ela lhe interessava essa discussão acerca da literatura
2. Depoimento de Ana Cristina no curso "Literatura de mulheres no Brasil", ministrado pela professora Beatriz Rezende, na Faculdade da Cidade, em 1983, publicado em Crítica e Tradução (1999).

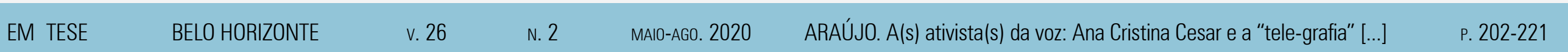

Teoria, Crítica Literária, outras Artes e Mídias 
feminina; pensar no que a identificava, desvinculá-la de uma literatura feita exclusivamente por mulheres. "Como falar de mulheres se estamos lidando com texto e não com a pessoa do autor - essa categoria fugidia que o texto escamoteia, com razão?” (CESAR, 1999, p. 245). Afirmar a existência de uma "literatura de mulher" acabava servindo como ponto de demarcação, tendo a ver com o tom, a postura ou o espaço social daquele que escreve. Escrever como mulher estaria relacionado com escrever à margem, mais próximo de uma transgressão, um modo menor, flexível, móvel. A escrita feminina estaria associada a uma forma mais livre, mais solta, que subvertia os padrões e normas sintáticas, ou pelo menos não se preocupava tanto com eles.

Ela problematizou essa discussão acerca do gênero na literatura, perguntando-se sobre os vícios da crítica que, invariavelmente, procurava fazer a sexualidade do autor corresponder à sua ma neira de escrever, ou atrelava o arquétipo do feminino à escrita de mulheres. Assim num artigo para a Folha de S. Paulo, em 12 de setembro de 1982, a propósito do novo livro de sua amiga Angela Melim, perguntava-se: “Angela virou homem?", referindo-se à mudança de tom dessa obra recém-lançada, identificando-a com uma escrita racional, organizada e articulada. Espécie de forma estável pertencente ao centro do sistema já existente, "masculinizada".

Em contrapartida, não associava o feminino à doçura e ao apaziguamento ou simplesmente às demandas da mulher feminista. A vida, e não menos a litera tura, a mbas têm um caráter eminentemente corporal e se definem pelo conflitivo. Viver é tocar, golpear, entrar em alguma classe de corpo a corpo, envolver-se diretamente com as dimensões da experiência. E o enfrentamento pode dar-se em vários níveis, desde a confabulação de inteligências - o que se vê nos artigos em que trava discussões literárias, reivindicando, com argúcia, seu lugar nas querelas intelectuais e eruditas - até o esforço estético quase agressivo empregado nos ensaios, traduções e em seu fazer poético exaustivo, deslindado hoje, mais ainda com a publicação póstuma de Antigos e Soltos (2008).

Mesmo que escrever femininamente se relacione à adoção de um tom de intimidade e de confidência, Ana Cristina adverte-nos contra a escrita sem revelações "biografílicas", consciente da impossibilidade de comunicação literária da intimidade, uma vez que ao tentar inscrever sua subjetividade, ela lhe escaparia de pronto. "Se você conseguir contar a tua história pessoal e virar literatura, não é mais a tua história pessoal, já mudou" 
(CESAR, 1999, p. 262). E são fartos os exemplos e advertências a esse respeito em sua obra:

Fica difícil fazer literatura tendo Gil como leitor. Ele lê para desvendar mistérios e faz perguntas capciosas, pensando que cada verso oculta sintomas, segredos biográficos. Não perdoa o hermetismo. Não se confessa os próprios sentimentos. Já Mary me lê toda como litera tura pura, e não entende as referências diretas. (CESAR, 2002, p. 120)

Olha, o Mário de Andrade tem uma distinção legal que é entre a intenção pessoal e a intenção estética. Por exemplo, intenção pessoal eu posso ter tido aqui quinhentas, acho que não interessa de jeito nenhum. Agora, intenção estética é alguma coisa que se revela no livro. Você pode ter pensado antes, ou pode ter pensado depois. (CESAR, 1999, p. 260)

\section{Nava rro,}

Te deixo meus textos póstumos. Só te peço isto: não permitas que digam que são produtos de uma mente doentia! Posso tolerar tudo menos esse obscurantismo biografílico. Ratazanas esses psicólogos da literatura - roem o que encontram com o fio e o ranço de suas antologias bara tas. Já basta o que fizeram ao Pessoa. É preciso mais uma vez uma nova geração que saiba escutar o palrar os signos. (CESAR, 2008, p. 16)
Para ela, a literatura consiste na criação de um universo próprio, autossuficiente. Todavia, não descarta as relações que guarda com o universo das coisas que quer evocar. É uma conversa com o mundo, porque é impossível retirar-se dele e de suas referências, de modo que fica claro que as obsessões pessoais do autor ta mbém participam da criação, mas apenas como matéria-prima. Há, com isso, uma rede de significantes que puxa muitos outros, como ela mesma diz, permitindo ao leitor ser iniciado em qualquer ponto dessa malha. Podem-se fazer as associações que se quiser com o que é evocado pela materialidade de seu texto. É para quem pegar, há muitas referências possíveis para enriquecer o processo de leitura, mas é impossível se chegar à Verdade do texto. Basta atentar para a ironia presente já no título de $\mathrm{A}$ teus pés e na declaração tergiversada da própria autora: “Não é irônico, gente. Olha, va mos lá. 'A teus pés'... Tem uma porção de coisas em 'A teus pés'. Eu gosto desse título, porque, em primeiro lugar, ele sugere uma devoção religiosa [...]. Depois ele sugere uma certa humilhação diante de... Ele sugere ta mbém um romantismo" (CESAR, 1999, p. 264).

\section{O CHAMADO TELE-GRÁFICO}

Assim como Ana Cristina, em sua inquietação, lançava indagações sobre as teorias e a cultura em circulação,

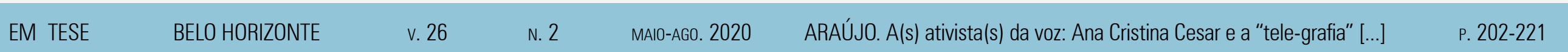

3. Vale a pena ressaltar que estamos tratando, aqui, da ironia no sentido caro a Kierkegaard, não à ironia de linguagem, como dando a entender algo contrário ou distinto do que o que se quer dizer. Isso, como se vê, a própria Ana Cristina também negava. 
contempora nea mente, Avital Ronell ta mbém coloca em movimento uma unidade de corpo-conhecimento. Suas aulas, conferências e manifestos têm um caráter performático em que a autora faz cruzar, em suas intervenções, o gestual, a conversa telefônica, a música, a rua, trazendo à tona personalidades e elementos culturais que hoje a distinguem no mero funcionalismo universitário.

Ronell realizou performances artísticas antes de enveredar pela via acadêmica e o mapeamento que faz do plano dos saberes na atualidade, a partir dos Ensaios para o fim do milênio, reunidos em Finitude's Score (1994) e em The Telephone Book (1989), propõe um diálogo incessante a partir das matrizes do pensa mento da diferença, mas não se contenta com a desconstrução operada, movendo-se na contracorrente, na ressonância da voz, da ambiguidade, colhendo interferências difíceis de catalogação. Permite, assim, a umentar a compreensão teórica e discursiva da poética de Ana Cristina, porque potencializa a criação de realidades e imprevisibilidades próprias à poesia, a través do ruído, da falha, da introdução da tecnologia como materialidade desejável no poema.

Uma rota alternativa para a investigação nos Estudos Literários, Avital atende a um chamado que dilacera, com a autoridade de uma presença súbita, um resoluto evento, que não se pode sujeitar a uma vontade nem à força de uma determinação previsível. O chamado, em erupção, como uma espécie de violência perpetrada contra uma projeção de destinatário ou destino, encontra-se, pois, essencialmente fora de qualquer controle, chegando a ser emitido apenas para marcar o que está fora de mão 4 . Convertendo o telefone em figura metonímica da tecnologia atual e das novas mídias: "Você não sabe quem está chamando ou que está para ser chamado, e você empresta, ainda, sua orelha, desistindo de algo, recebendo uma ordem. É uma questão do poder de resposta" (RONELL, 1989, p. 2). Quem responde a uma chamada telefônica precisa prestar contas daquilo que o cha mado lhe vai impor. Um chamado involuntário, a convocação de uma voz. Onde está o outro? Quem quer falar? Falar o quê? Para quem?

O chamado exige, assim, uma presença, pede uma interlocução, busca um destinatário, vai dirigido a quem atender. Faz a conexão de subjetividades, com todas as implicações que isso envolve, coloca em contato uma rede de vozes num plano de ação e resposta. Mais que isso: hoje, superando outras épocas, mistura meios de propagação, conta minação, no dizer da autora. Porque, estando abertos às novas tecnologias, estaremos, ta mbém, dispostos a redimensionar o conta to exigido - uma
4. Cf. Ronell, 1989, p. 32

5. Traremos as citações traduzidas ao português, no corpo do texto, para facilitar a interlocução com as obras citadas e, entre parênteses, a referência para sua localização no original.

EM TESE BELO HORIZONTE $\quad$ v. $26 \quad$ N. 2 MA10-AGo. 2020 ARAÚJO. A(s) ativista(s) da voz: Ana Cristina Cesar e a "tele-grafia" [...] $\quad$ P. 202-221

Teoria, Crítica Literária, outras Artes e Mídias 
vez que este já não se vai dar apenas no um a um, tampouco reduzido ao â mbito da escuta telefônica, ou sem a possibilidade de saber quem chama, haja vista os identificadores de chamada -, o que nos leva a pensar, ainda no seu alcance, que pede a disposição do corpo todo, não meramente o ouvido, mas até mesmo as sensações, tor nadas muitas vezes sinais gráficos, utilizadas no textual da Internet, nos memes e nos stickers de hoje em dia.

Como se vê, a ativista da voz compreende esse contato e o a mplia, sob os signos da nega tividade e da dissensão, orquestrando, a partir das contribuições da música e da filosofia, o papel do telefone, protótipo para a comunicação. Desestabiliza, pois, a imagem e tematiza a voz, a conversa, o som, a digitação, o texto; promove o encontro das linguagens em outros meios de difusão. Compartilha a errância, torna-se porta-voz de uma discursividade que não entra apenas pelo labirinto do pavilhão a uricular, mas encontra seu lugar onde parecia haver uma singular separação. Implementa a lógica da simultaneidade.

Nessa ligação, Ronell faz vibrar acordes de várias áreas do conhecimento, levanta campos de discussão filosófica que pedem a conexão e a atenção do leitor-espectador-ouvinte, para que possa extrair dos silêncios tele-gráficos a condição de possibilidade que excede o som, porque conta com as interrupcões, as falhas, os ruídos, as rasuras, os arranhões, os ecos e as lacunas. Mostra outros usos do telefone. A leitura a partir do silenciamento, das fendas, traz para a discussão um lugar proveitoso para a virtualidade, a vivacidade da sombra, o corte e a costura de novos e usados, antigos e soltos, a té o surgimento de uma porção considerada antes invisível, borgea namente fecunda, desconhecida da maioria, a urdidura do poema, os bastidores da escrita - a pasta rosa, no que conhecemos da obra de Ana Cristina Cesar.

"O telefone vem até você e lhe acaricia, ou pode ser usado como uma arma, uma arma sem indícios, uma arma apontada para a sua cabeça" (RONELL, 1994, p. 34). Ele faz a comunicação do rumor da rua e da sinfonia da orquestra. Ele cria um espaço de significantes fragmentados, produzindo uma interseção onde as linhas públicas se cruzam com as mais privadas, num todo harmônico. E Ronell, via telefone, conecta livro, poética e filosofia. Realiza um trajeto dotado de extensão, um trabalho ensaístico que envolve a captura dos processos de escrita e pensamento, intervenção cultural, como veremos a seguir.

O que fazer, pois, com o que existe? Como intervir? Como conseguir que, novamente, haja uma primeira vez

EM TESE BELO HORIZONTE $\quad$ v. $26 \quad$ N. 2 MAI0-Ago. 2020 ARAÚJO. A(s) ativista(s) da voz: Ana Cristina Cesar e a "tele-grafia" [...] $\quad$ P. 202-221

Teoria, Crítica Literária, outras Artes e Mídias 
na já gasta discussão filosófica e cultural? Alan Pauls comenta que Borges, por seu turno, não reduz seu pensamento e intervenção a uma apologia da reescrita, como podería mos ser levados a crer, e o conceito de livro e, consequentemente, de obra de arte, por tudo que vimos, começa a se colocar como verdadeiramente borgea no. Ronell, também, por seu lado, não recai no imobilismo essencialista da reprodução epistemológica. Ao contrário, parte para o estudo e a experimentação com a linguagem lança mão da ontologia e da interpretação como forma de compreender esse estado de ser visceral sujeito-objeto que coloca em evidência a desaceleração da diferença. A fonte diferencial não se expande porque não dá conta do reconhecimento do uno-negativo, que continua pendente, relegado à sombra, adiado em seu reconhecimento como outro, mantido à distância, mas disposto a se enunciar a qualquer chamado, translúcido, ao vivo.

Borges opera sobre o texto e sobre o contexto, sobre as condições nas quais se apresenta um texto ao leitor, no momento de sua edição, ou reedição, adulterando esta última, conforme lhe aprazia, como fez tantas vezes. Foi, em certo sentido, o que aconteceu, no momento em que foram trazidos à luz os Antigos e Soltos, de Ana Cristina Cesar - último dos livros póstumos da autora, publicado em 2008. Não há como responder à pergunta feita acerca da intervenção ou, melhor, a resposta é móvel, inquietante, segundo o autor argentino, já que a identidade de algo escrito não se define por uma série de atributos, mas pela relação que mantém com os contextos nos quais aparece ou com a época de seu surgimento e/ ou edição. Portanto, editar uma obra póstuma como Antigos e Soltos, relegada tanto tempo à consulta privativa apenas, permite uma série de indagações sobre o fazer poético e a concepção de poesia na atualidade, incita a um olhar sobre a individualidade. De igual modo, merece um cuidado e um apuro técnico, que vêm sendo pouco a pouco abandonados, contemporaneamente, sobretudo quando se trata de escritos destinados à publicação e seus rascunhos, primeiras versões, verdadeiro laboratório da construção estética.

Nesse sentido, Antigos e Soltos (2008) traz algo diferente. Nas versões em fac-símile dos textos inacabados da autora, deixa entrever a poética de alguém que trabalha com frases, com palavras, com a discursividade, com a elocução do eu. Um artista de posse de um cinzel, elaborando versões do que seria a Obra. Entrevê-se, assim, o especialista de uma arte conceitual e respeitosa, cada dia mais rara, pois que, contemporanea mente, quase não há marcas do que, não obstante, seria capaz de uma extraordinária revelação de manipulação de conceitos e contextos. ${ }^{6}$ 
7. Ana C. era o modo como a poeta Ana Cristina Cesar costumava assinar seus textos, mas essa contemporânea converteu-se pouco a pouco em personagen conceitual, como destacariam Deleuze \& Guattari (1992), criando por alusão uma referencia que deve ser reconstituída pelo deve ser reconstituida pelo de Bernardo Carvalho. Ana C. surge, portanto, não como uma personificação abstrata, um símbolo ou uma alegoria, mas vivendo, insistindo, fazendo pensar, colocando em dúvida certas verdades. Desse modo, não interessa apenas a simples identificaçao com um personagem histórico ou literário, praticamente biográfico, mas se evoca um potencial de enunciação a partir do significado dessa nomeação, que, desde já, encerra uma ambiguidade: trata-se ou não da poeta Ana Cristina Cesar?
É como se escrever fosse isso - continuaria o a nalista de El factor Borges (2004) - mudar coisas de lugar, recor tar e colar, extrapolar e fazer enxertos, deslocar e repor expatriar e arraigar, separar e inserir. Definir uma personagem ou urdir uma trama é, então, criar uma a mbiência, produzir um contexto a tivo e criativo capaz de promover uma intervenção. Para Borges, o ponto de inflexão produtivo de sua obra foi, sem dúvida, Pierre Menard, autor del Quijote, uma personagem criada, um escritor menor, francês, reverenciado por ba ronesas decadentes, que enriquece a cultura através do processo de leitura e intervenção em uma das maiores obras do cânone literário espanhol, a partir da apropriação de três capítulos da obra de Cervantes, escrita em pleno século XVI. No entanto, tal façanha se dá em princípios do século XX.

A diferença de contextos se encarrega de todas as implicações transcorridas ao longo desses mais de trezentos a nos de publicação, carregados de complexos processos, acontecimentos e transformações pelos quais passou a humanidade e a vida cultural como um todo. É o que o enche de sentidos e usos inesperados, assim como acontecerá com a personagem Ana $C^{7}$, no texto do romance Teatro (1998), de Bernardo Carvalho, enriquecida a partir da leitura e da possível identificação com a poeta Ana Cristina Cesar, a despeito do anacronismo deliberado e das atribuições falsas. Ambos - Jorge Luis Borges e Bernardo Carvalho - la nçam mão do mesmo recurso, com resultados diferentes, transformando suas personagens em conceitos limpos e eficazes, independentes da obra, livres o suficiente para entrar e sair, para transitar em todos os espaços, tempos e até mesmo sexualidades, dadas as diferentes personalidades sexuadas assumidas em Teatro (1998) por Ana C.

Dessa maneira, vemos como ela se converte em palavra desejada, em sua anterioridade, aberta à rumorologia, estudo e experimentação, consciente de que o eu pode não estar ali, no fone em resposta, no dizer de Ronell, mas gravado nas mensagens de áudio, pronto para ser acionado e reproduzido. Voz sem corpo, corpo sem voz, erráticos, acionados e reproduzidos em cada leitura, ocupantes do lugar preenchido pela identidade. Pois, como vimos, a obra de Ana Cristina despreza os arroubos biográficos e uma personagem-narradora retratável, de contornos fixos, centrada. Para propor, como destaca Ítalo Moriconi: "[...] a dissolução do eu romântico na mascarada errante do sujeito poético instaurada pelo modernismo, configurando uma alternativa à 'desaparição elocutória do eu' proposta e realizada por Mallarmé” (MORICONI, 1996, p. 99). Legitima, como pressuposto, um sujeito poético estilhaçado, vacilante, visualmente descentrado, num 
8. A expressão foi cunhada pelo próprio Borges, para designar a or, segundo Pauls, 2004 , p. 126. poema de palavras soltas, declarações telegráficas, relatos reticentes, cortes.

\author{
Vacilo da vocação \\ Precisa ria trabalhar - afundar - \\ - como você - saudades loucas - \\ nesta arte - ininterrupta - \\ de pintar - \\ a poesia não - telegráfica - ocasional - \\ me deixa sola - solta - \\ à mercê do impossível - \\ - do real. \\ (CESAR, 2002, p. 58)
}

O operador, leitor-espectador-ouvinte dessa escrita performática, parte em busca, com seus próprios esforços, da extensão dessa fala, mas se encontra, invariavelmente, com a a mbiguidade irônica que explode entre as lacunas deixadas pelo contratante verbal ${ }^{8}$. Aí se propagam rumores, indecisão: solta - verbo ou adjetivo? À mercê do impossível, do real, ele a funda nessa arte ininterrupta, enreda-se pintando saudades loucas, entre fragmentos, dea mbulações, périplos. Completa o que falta, exercitando seu excesso. É um "processo inacabado, cujo alinha mento se dá, justa mente, pela não-identificação com os lugares destinados às contradições da subjetividade e da realidade político-social" (VASCONCELOS, 2002, p. 203).

Interessante notar, nesse exercício borgeano, como Ana salta, em suas análises, de um autor a outro, ba ralhando bibliografias, navega ndo entre línguas, culturas e formas de saber heterogêneas, multiplicando os focos de observação de um problema, analisando épocas, tradições e mitologias diversas com o intuito de colocar em evidência a radical instabilidade que afeta toda relação de propriedade com o saber e com a cultura. Cultura dos que não têm cultura, cultura de divulgação, resumida, traduzida, enciclopédica, espaço de perplexidade, de inquietude e de ameaça. Estão todos em busca da relação que o signo estabelece com a estrutura verbal onde se encontra inserido, pronto para ser recuperado em função da leitura.

Entende-se, pois, o leitor - identificado a té agora, sem o desprezo de suas faculdades de espectador e, ultimamente, ouvinte - como o "lugar borgea no que inclui figuras tão diversas como o outro, o interlocutor, o confidente, o destina tá rio do rela to, o herdeiro, o duplo" (PAULS, 2004, p. 127). O grande agente contextual que abre o sentido a todas as forças que o produzem, afeta m-no e o determinam. Em suma, o que põe para funcionar a ironia, restituindo ou inventando contextos; o que franqueia a

EM TESE BELO HORIZONTE $\quad$ v. $26 \quad$ N. 2 MAI0-Ago. 2020 ARAÚJO. A(s) ativista(s) da voz: Ana Cristina Cesar e a "tele-grafia" [...] $\quad$ P. 202-221

Teoria, Crítica Literária, outras Artes e Mídias 
9. Referência a um dos ensaios de Avital Ronell reunido em Finitude's Score (1994).

10. Cf. Vasconcelos, 2002, p. 207 terra borgeana: o espaço existente entre dois registros, duas percepções, duas formas de raciocínio, duas linguagens. O que chama e o que atende ao chamado do telefone.

Tanto que Avital Ronell e Ana Cristina não querem simplesmente a diferença pela diferença e inscrevem suas obras no ponto de intervenção dessa fronteira movente, no espaço da rua, entre os signos e o poder, encaminhando-se para estratégias de intensificação da escuta-resposta a um chamado de feminização. A proliferação por contiguidade, que não agrupa nem sistematiza a diferença em derivados, mas potencializa uma alteridade radical, com percursos pela tecnologia adentro, aguça a receptividade e o anonimato, descentralizando e exaurindo o ato de pensar, de modo a se observar a impessoalidade do street-talk ${ }^{9}$, o mantém contato inicial - constante nas conversas e no modo de se despedir de Ana Cristina Em suma, a suplementação derridea na, o ruído, a sombra. Um scratch/montagem de espaços e temporalidades. Atuação no intervalo, na interrupção, dentro do andamento da voz e da caminhada de alguém que se mostra como pensador durante a passagem de si, de muitos outros diferentes, cada vez mais diferentes. ${ }^{10}$

Nesse sentido, ler e caminhar são dois movimentos de um mesmo vício, um exercício e um programa. Traçam um percurso subjetivo. Daí entendermos a dromomania de nossos autores e teóricos e suas incursões pelo mundo. Caminhar é uma operação múltipla: é, ao mesmo tempo, uma maneira de ler sobre a marcha dos signos de uma cidade desconhecida, uma forma de ocupação física e um modo de reinscrever sobre o plano urbano, uma disposição para a deriva. É preciso, então, ler a partir das margens, das zonas-limite, dos arrabaldes, das transições, em busca de encontrar o pensamento de alguém e tropeçar com ele, para, enqua nto se caminha, ler ou escrever e, por que não, apropriar-se dele.

Há, portanto, o traço do urbano e da conversação, a tentativa de captar o ritmo da cidade, da rua e do diálogo. A fala cotidiana, sem ser a reprodução dialógica, mas a produção de algo melódico e harmônico, frenético. Há um espaço multiterritorial, multirrítmico, multicêntrico, que aponta para várias direções, um arra njo de múltiplas texturas. Há um processo de produção de realidades abertas ao que está fora, expandindo-se, errando, migrando em escapadas, fugas, tropeços, conexões atualizadas que não buscam apaziguar as heterogeneidades reunidas. Em outras palavras, a suplementação da linguagem, a partir de dentro, com um código próprio, uma língua intensiva, em virtude da afasia do sistema linguístico dominante. $\mathrm{E}$ Ana antecipa o projeto de Ronell, prima pelo trabalho da

EM TESE BELO HORIZONTE $\quad$ v. $26 \quad$ N. 2 MAI0-Ago. 2020 ARAÚJO. A(s) ativista(s) da voz: Ana Cristina Cesar e a "tele-grafia" [...] $\quad$ P. 202-221

Teoria, Crítica Literária, outras Artes e Mídias 
escrita, pelos efeitos da leitura e da criação de sensações; retoma a singularidade que conecta a todos, que dá voz a muitos.

\section{Lá fora}

há um amor

que entra de férias.

Há um embaçamento

de minhas agulhas

nítidas diante

dessa boa bisca

de mulher.

Há um placar

visível em altas horas,

pela persiana deste hotel

fatal, que diz: fiado,

só depois de amanhã

e olhe lá,

onde a minha lâmina

cortante,

sofrendo de súbita

cegueira noturna,

pendura a conta

e não corta mais,

suspendendo seu pêndulo

de Nietzsche ou Poe por um nada que pisca

e tira folga e sai

afiado para a rua

como um ato falho

deixando as chaves

soltas

em cima do balcão.

(CESAR, 2002, p. 75)

Nesse sentido, catalogando múltiplas referências, a a náfora do "há" registra, já na complementaridade com o título do poema de Ana Cristina, que é ao mesmo tempo título e primeiro verso, tudo o que há lá fora, embaçado ou nítido, visível ou cegueira noturna. A paisagem da rua intervém pelas luzes de neon piscando, reverberando o trocadilho entre fiado/afiado, mostrando a lâmina que corta palavras nos versos e as deixa soltas numa única linha: cortante/soltas - alinhavadas às precedentes e às subsequentes. Como um a to falho, sem chaves, dispostas em cima do balcão, o campo semântico vai construindo-se pendularmente, evocando o pêndulo de Foucault, que em sua originalidade detém a liberdade de oscilar em qualquer direção, sem plano pendular fixo. Assim, a rotação do plano do poema determina, a naloga mente, a latitude do local da experiência, sem nenhuma observação astronômica exterior, uma vez que pode conter as 
experiências interiores - das leituras filosófico-literárias empreendidas, de Nietzsche à tradução dos contos de Edgar Allan Poe.

É o que Ronell, fascinada pelos ruídos da rua, realiza a partir do telefone. $O$ conta to entre o dentro e o fora, a periferia e a "great house", movendo-se, recepcionista de chamadas, "hostess", a nfitriã, estabelecendo relação, saturando de performance as fendas. Convoca as ausências, os interstícios sombrios a se manifestarem, a mostrarem que respiram; expõe a epistemologia da rua, do rumor, da escória; transcende os guetos, sintetiza o disjuntivo, batendo-os no mesmo liquidificador, como se vê nos ensaios Finitude's Score, Street-talk e The Worst Neighborhoods of the real. Desse modo, sob a sombra da negatividade, o rumor a tua para capacitar o território onde se encontra, fricciona ndo o que separa a criação da destruição; numa palavra: ensinando a errância. O telefone significa aqui o conta to com o Outro fendido, conta to nunca quebrado, nem claramente rompido. Vozes que acenam caminhos do pensamento abertos na linguagem.

"Tantos poemas que perdi. Tantos que ouvi, de graça, pelo telefone - taí, eu fiz tudo pra você gostar [...]" (CESAR, 2002, p. 72), "Movido contraditoria mente por desejo e ironia não disse mas soltou, numa noite fria, aparentemente desalmado: - Te pego lá na esquina, na palpitação da jugular, com soro de verdade e meia, bem na veia, e cimento armado para o primeiro andar." (CESAR, 2002, p. 66), "A voz em off nas montanhas, inextinguível fogo domado da paixão, a voz do espelho dos meus olhos, negando-se a todas as viagens, e a voz rascante da velocidade, de todas três bebi um pouco sem notar como quem procura um fio" (CESAR, 2002, p. 73)

Voz e corpo que alteram suas condições em função do contato que se quer estabelecer, do que se quer dizer, dispondo de si, ignorando as margens, buscando o gestual, compondo os fios dos sentidos da performance. Mediação da voz na estrutura do corpus, reflexão do objeto artístico e de uma forma de ser que desloca a representação em função da simulação e da fabulação. Tudo se pronuncia em vista de outra temporalidade e de outro movimento, ganhando uma espacialidade, um dinamismo verbo-motor, tele-gráfico.

\section{CONCLUSÃO}

É como nos encontramos: numa linha de segmentaridade em contiguidade de territórios, unidos pela tele-grafia de Ana Cristina Cesar, que nos colocou a todos em contato e, por isso, nossos segmentos se afina m, conjugam-se num fluxo maleável, numa escala intensiva, numa 
11. Comentário feito a partir da novela In the Cage (1898), de Henry James, nos Mil Platôs, v. 3. indeterminação objetiva. Afinal, como diriam Deleuze \& Guattari (1995) ${ }^{11}$, é certo que duas linhas não param de interferir, de reagir uma sobre a outra, e de introduzir cada uma na outra uma corrente de maleabilidade ou mesmo um ponto de rigidez. Elas mostram como o diálogo ou a conversação obedecem aos cortes de uma segmentaridade fixa.

Há, portanto, vários movimentos, fissuras que não param de se manifestar; há toda uma subconversação na conversação, evidenciando que uma perspectiva corpórea encontra seu equivalente numa inflexão da voz. Uma percepção cenestésica que exige um esforço considerável da subjetividade. Nessa civilização que tende a ignorar outros procedimentos de registro, "um laço funcional liga de fato à voz o gesto: como a voz, ele projeta o corpo no espaço da performance e visa a conquistá-lo, saturá-lo de seu movimento" (ZUMTHOR, 1993, p. 245). Essa performance é jogo, espelho, desdobramento do a to e dos atores, das subjetividades: do corpo do artista, filósofo, teórico, crítico, poeta ao corpo da obra de arte, filosofia, teoria, crítica, poesia. Ali está o lugar máximo da percepção da expressão. Vida que não esgota suas possibilidades, reverberando entre o corpo e a voz a articulação da cena cultural, sob novas formas de compreender o estético e de reconhecer suas múltiplas gradações. O sentido de um texto dando-se em presença e no jogo de um corpo humano.

Porque Ana Cristina, em intercessão no Teatro de Bernardo Carvalho, por exemplo, é portadora de uma linhagem performática, uma escrita simulada e fabula$\mathrm{da}$, que, ao produzir estra nhamento, vai dotando-nos de sensibilidade para aguçar nossa percepção de mundo e instaurar outros planos de possibilidade e de leitura. Em a mbos, vemos a linguagem do ponto de vista da variedade de suas injunções, articulações, flexões, até sermos dotados da capacidade de enxergar, através das sombras, a materialidade repleta de significados. Com eles, e com sua comunidade textual, a rriscamos em vista de um projeto coletivo, a fim de: "Abrir de tudo quanto é jeito para novas vias - por vezes linhas de fuga minúsculas, e outras vezes possibilidades de trabalhar em escala maior" (GUATTARI, 1987, p. 67).

Assistimos, assim, à tentativa de quem insiste com os próprios corpos em construir algo de vivo, modifica sua relação com o mundo, acaba com as formas de alienação, a travessa as estratificações existentes, para "[...] fazer com que os corpos, todos os corpos, consigam livrar-se das representações e dos constra ngimentos do 'corpo social', bem como das posturas, atitudes e comportamentos 
estereotipados" (GUATTARI, 1987, p. 43). Para alcançar o exercício da escrita, da voz, do contato, da interlocução a emergência de outras práticas discursivas, de novos territórios existenciais coletivos, o elogio da sombra que enriquece de modo contínuo sua relação com o mundo.

E Ana Cristina abre-se para essa processualidade criativa, porque queria um engajamento ético-estético enunciativo e polifônico. Era o que afirmava Armando Freitas Filho, amigo da poeta, na noite do lançamento de Antigos e Soltos, no IMS, no Rio, quando dizia que à medida que a morte da autora se distanciava, sua obra se aproximava de seus leitores. "Esta mos fazendo o caminho do luto fechado à janela aberta" - mostrando o convite daquele evento, que trazia Ana, de rosa, não por acaso - alusão ao conteúdo daquela pasta rosa, publicado àquela altura - deixando-se fotografar, como gostava, de óculos escuros, na janela; comparando-o a outros convites - negros, enlutados - de diferentes momentos celebrativos, depois da morte da autora. Para ele, a tristeza da ausência va cedendo lugar à alegria, evocada pelos jovens que vão tendo acesso à sua obra e produzindo suas respectivas leituras. A presença desse público ali, naquela noite de lançamento, e de todos os autores retomados por ela reforça, ainda hoje, sua personalidade literária.
A imagem fugidia de Ana Cristina e sua literatura sempre em movimento ainda instiga $\mathrm{m}$ a curiosidade dos voyeurs ${ }^{12}$, da imprensa que insiste em ver sua obra como trança de ficção e confissão. Em contrapartida, preferimos descobrir os bastidores de seu work in progress, no dizer da organizadora de Antigos e Soltos, Viviana Bosi, quando abrimos a pasta rosa e vemos se desdobrarem várias versões de seus textos. Preferimos encontrar o trabalho árduo de quem realmente "embaralhava" muito as palavras, cartas marcadas, antes de passá-las à leitura, com intensidade, presença e verdade nos rabiscos, rasuras - os scratches de Ronell -, registrando as fendas, os fragmentos e as fraturas expostas, o segreda mento e a secreção de poesia que emanam do corpo da poeta e vão se alojando em nós. A um só tempo: esconderijo, revelação, trajetória, descaminho, silencia mento e ruído - street-talk.

É assim que Antigos e Soltos, em dueto com o anterior, Inéditos e Dispersos, vinha à tona, tomando emprestado o nome de uma das seções da pasta sanfonada - onde a autora arquivava seus protopoemas, cartas e bilhetes - descoberta no fundo de um armário, depois guardada carinhosamente pela família (não sem antes serem meticulosamente numerados os originais pela mãe zelosa), até ser confiada ao Instituto Moreira Salles. A reprodução em fac-símile da diversidade de papéis utilizados pela
12. "Afinal, revirar uma pasta escondida é um pouco isso, guardados de uma poeta reconhecida Darmo-nos a licença de um certo voyeurismo e a possibilidade cada vez mais necessária do espanto, palavra solitária que Ana C. desenha em letra branca numa página solta" (JAFFE, 2008, E9).

EM TESE BELO HORIZONTE $\quad$ v. $26 \quad$ N. 2 MAI0-A60. 2020 ARAÚJO. A(s) ativista(s) da voz: Ana Cristina Cesar e a "tele-grafia" [...] $\quad$ P. 202-221

Teoria, Crítica Literária, outras Artes e Mídias 
a utora também expõe o ca rá ter compulsivo dessa escrita em diáspora, em várias direções e matizes diferentes, sobre a superfície da página nua, dando a impressão de alguém que escrevia obsessivamente, dada a variedade de folhas soltas. Bem ao gosto de Walt Whitman, em Leaves of Grass (1860), traduzido por Ana Cristina, dizendo-se cair dessas "folhas de relva" nos braços do leitor e, por conseguinte, como não podia deixar de ser, aos seus pés, com o último verso desgarrado, misturando ela mesma silêncio e signos.

lá onde o silêncio é relva

de lá corrói-se hoje o texto

corrói-se porque hoje o aga rra

o pré-texto que nunca se alheia

e o a ntecede em silêncio

lá onde os signos me esquecem

separados pré-texto e soneto

esqueço que os tenho alheios

à pressa de separá-los

esqueço que lábios e signos

sem pressa se fazem relva

e inscrevo desconhecido

o último verso desgarrado:

(CESAR, 2008, p. 82)
Por isso, diante dessa antiga e nova fortuna crítica editorial da autora, solta e reunida ao longo dos a nos, cosida na melhor trama de seus fios discursivos, que chegava, indistinta mente, às mãos dos leitores ${ }^{13}$, mais vale reconhecer esse reescrever constante, maníaco, dromoma níaco - tão caro a Bernardo Carvalho, a Jorge Luis Borges e a Avital Ronell -, como quem quisesse tornar a vida escrita quase sem distinção. Alguém que vai construindo seu próprio movimento e temporalidade/espacialidade. Desse modo, mais importante que emitir um juízo valorativo sobre esse conteúdo, que não se pretendia publicável, cabe-nos apreender o fazer poético de Ana Cristina, através de seus retalhos de agenda, apontamentos de aula redações, desenhos, diários de bordo de suas viagens, anotações íntimas dispostas em várias seções: Prontos, mas rejeitados (grupo de escritos mais bem acabados, que indicavam intenção de futura publicação); Inacabados; Inacabados 2; Rascunhos/primeiras versões; Cópias; Antigos \& soltos; "O Livro".

Além disso, como já foi bem salientado pela organizadora, no prefácio à edição dos Poemas e prosas da pasta rosa:

Hoje em dia já não se enviam tantas cartas nem se guardam longamente os primeiros rascunhos de um poema. Também por isso os editores resolveram reproduzir os fac-símiles, para que
13. Alguns textos já haviam sido publicados em jornais e revistas por alguns estudiosos da obra de Ana Cristina. 
14. Certamente se pode perceber (e) Banque à figura de Platáo e o embora também se note que a autora se nutria dos versos dos pensamentos de suas outras referências literárias e filosóficas, evocadas constantemente em seus textos. a proximidade quase imediata do manuscrito com a mão que o escreveu possa ser apreendida pelo leitor. (BOSI, 2008, p. 10)

De sorte que ta mbém nós, a partir desses documentos, seja mos chamados a participar da empreitada origina da autora, que continua a nos convidar para o confronto com as variantes de um mesmo texto e a decisão acerca dos sentidos ou da versão preferida, permitindo-nos optar, inclusive, pelo que havia sido rejeitado.

Neles, aqui e ali, ainda se pode ver a "intromissão consentida" de outras letras a migas cruzando com seu texto, emitindo suas opiniões. Estamos, pois, felizmente, diante do processo vivo do plano de composição de Ana Cristina, convocados a adentrar a malha; entretanto, calça ndo com ela as luvas - íntimos e reservados; aprendendo suas receitas com títulos de poemas ou seus pequenos poemas com títulos de pratos culinários - todas as igua rias. ${ }^{14}$

$$
\begin{aligned}
& \text { Banquete } \\
& \text { cheguei a perder o } \\
& \text { paladar } \\
& \text { de tanto pensar que } \\
& \text { comia } \\
& \text { (CESAR, 2008, p. } 79 \text { ) }
\end{aligned}
$$

Tudo cosido e bem cozido, a despeito das rupturas e oscilações, justaposições e montagens. Estamos muito próximos, mas sem consentimento para documentários, uma vez que não nos encontramos habilitados a revelações confessionais e já fomos advertidos sobre as pretensões de verdade desse tipo de discurso. Relegados ao terreno da ironia, franquea mos a escuridão, vimos o "palrar dos signos”, entre a disjunção da experiência pessoal e a explosão do simulacro. Conservamos, nitidamente, como bem pontuou Avital Ronell, os esga rçados da rasura e do rascunho, enovelados em perturbações tele-gráficas, da tessitura urbana ou do mar da performance, posto que navegamos com ela na "naufrágil"15 do devir.

Comemos, fartamo-nos e nos deliciamos, qua ndo nos depara mos com algumas versões já publicadas em outras obras, por vezes preteridas como estava m, quedando de molho a té a tingir o ponto. E, para finalizar, começamos do início desses Antigos e Soltos, conhecendo Navarro. Como ela, um interlocutor, uma personagem com quem travamos contato, com quem partilhamos a angústia de não terminar o que parecia mesmo não ter fim, para essa que extrapolou os limites da criação, construindo e tornando-se personagem, intercessora. Em busca de alívio para as ansiedades que o silêncio nos impõe.
15. Cf. desenho da autora, à página 178, de Antigos e Soltos (2008).
EM TESE
BELO HORIZONTE
v. 26
N. 2
MAIO-AGO. 2020
ARAÚJO. A(s) ativista(s) da voz: Ana Cristina Cesar e a "tele-grafia" [...]
. 202-221

Teoria, Crítica Literária, outras Artes e Mídias 
Nava rro,

Hoje produzi um personagem que já me alivia as ansiedades do silêncio. Hesito ainda sobre o sexo e a idade que lhe darei. Mas não há porque preocupar-me: essas questões já foram devidamente resolvidas por Orlando. Temo apenas por seu futuro: sonha criar páginas imortais mas tortura-se na improdutividade. Receio que também este problema tenha sido superado pela grande Woolf. Quem diria, aqui vou eu incorrendo no delito de exaltação de Personalidades! Desde que li Pessoa porém não me deixa o tiro de sair pela culatra. Caluda que ouço a porta! Eram os velhos que voltavam à tenda celeste. Sem eles Deus se sentiria órfão, com eles tenho a certeza sente-se divino. Falava-te da personagem relegada, a quem já conferi família. Pois me parece que aprecia o mar e as covas, mormente os moluscos retorcendo-se nos seus abrigos. Cre imitá-los em papéis, mas não encontra ponte entre tais seres tais formas. Tal ser tal forma, já dizia minha tia a quem amava mas espelhos solícitos desmentiram-me num piscar de olhos. A figura de uma tia amada é porém ainda maior que o desespero das evidências... Que venham a mim as colagens e seus delírios. Ou as criancinhas, cujos olhares me enternecem os tímpanos exaustos. Falava-te de vísceras. Guarda este segredo; esta secreção. Não,

(CESAR, 2008, p. 18-20).

\section{REFERÊNCIAS}

BORGES, J. L. Elogio da Sombra. Trad.: Carlos Nejar. Rio de Janeiro: Globo, 1970

BORGES, J. L. Pierre Menard, autor del Quijote. In

Ficciones. Buenos Aires: Alianza Editorial, 1945. p. 47-59.

BOSI, Viviana. Prefácio. In: CESAR, A. C. Antigos e Soltos: poemas e prosas da pasta rosa. (Org). Viviana Bosi. São Paulo: Instituto Moreira Salles, 2008. p. 9-13.

CARVALHO, B. Teatro. São Paulo: Companhia das Letras, 1998.

CESAR, A. C. Antigos e Soltos: poemas e prosas da pasta rosa. (Org). Viviana Bosi. São Paulo: Instituto Moreira Salles, 2008

CESAR, A. C. Crítica e Tradução. São Paulo: Ática, 1999

CESAR, A. C. Inéditos e Dispersos. São Paulo: Brasiliense 1985

CESAR, A. C. A teus pés. São Paulo: Ática, 2002. 
DELEUZE, G.: GUATTARI, F. Mil Platôs: capitalismo e esquizofrenia. Vol. 3. Trad. Aurélio Guerra Neto, Ana Lúcia de Oliveira, Lúcia Cláudia Leão e Suely Rolnik. Rio de Janeiro: Ed. 34, 1995

DELEUZE, G.; GUATTARI, F. O que é a filosofia? Trad. Bento Prado Jr. e Alberto Alonso Muñoz. São Paulo: Ed. 34, 1992. GUATTARI, F. Revolução Molecular: pulsações políticas do desejo. São Paulo: Brasiliense, 1987.

JAFFE, Noemi. Rascunhos revelam Ana Cristina Cesar. Folha de S. Paulo, $1^{\circ}$. de novembro de 2008, Ilustrada, E9.

MORICONI I. Ana Cristina Cesar: o sangue de uma poeta. Rio de Janeiro: Relume-Dumará, 1996

PAULS, A. El factor Borges. Barcelona: Anagrama, 2004

RONELL, A. Finitude's Score: Essays for the end of the millennium. Lincoln e Londres: University of Nebraska Press, 1994

RONELL, A. The telephone book: Technology -

Schizophrenia - Electric Speech. Lincoln: University of

Nebraska Press, 1989
SARLO, B. Jorge Luis Borges, um escritor na periferia.

Trad.: Samuel Titan Jr. São Paulo: Iluminuras, 2008.

VASCONCELOS, M. S. Derivados da diferença: Estenofonia. In: SCARPELLI, M.; DUARTE, E. Poéticas da Diversidade. BH: UFMG/FALE/Pós-Lit, 2002, p. 199-208.

ZUMTHOR, P. A letra e a voz. São Paulo: Companhia das Letras, 1993.

Recebido em: 13-05-2020 Aceito em: 21-12-2020 